Sean Nicholas

MCRP, Cal Poly

Vicente del Rio

PhD, Professor

City and Regional Planning, Cal Poly

\section{Park Marina Area Concept Plan Riverfront Revitalization in Redding, CA}

Through a community outreach effort and in a true learn-by-doing fashion, in winter 2005 CRP's Graduate Planning Project Lab developed a concept plan for the revitalization of an important riverfront area in Redding, CA. Their vision and proposals were successful in responding to all stakeholders' expectations, and received full support from the local community. The design process included an innovative on-line survey which guaranteed significant inputs from the community.

One of the fundamental goals in planning education is teaching students how to develop a specific plan, including the maximum exposure to the urban design process and plan implementation. This goal gets harder if one considers the need for a hands-on experience in the context of a graduate professional program where most students do not possess a planning or a design background, and when the quarterbased system makes long studios impossible. The graduate student class of 2005 reached this goal and advanced on CRP's learn-by-doing pedagogy and on community outreach by playing a major role in process towards the development of a riverfront site in Redding, CA.

The proprietors together with a local architect invited the College of Architectural and Environmental Design to develop a concept plan for an area by the Sacramento River. The goal was to conceptualize how it could be developed and the riverfront revitalized through a long-term process that would respond to city policies and to stakeholders expectations, while serving as a catalyst for community discussion. The City and Regional Planning Department accepted the challenge through its graduate Planning Project Lab (CRP 553) class of 2005, which included 19 graduate students (second year, MCRP) and one undergraduate senior (BSCRP). The Park Marina Drive Concept Plan develops a unique approach for the revitalization of Redding's most important asset. The quality and feasibility of the work done by the class prompted the city to support a community discussion process for the implementation of the plan's vision and design concepts.

\section{The Project}

The City of Redding is located on the banks of the Sacramento River in Northern California. The Kutras family owns a 27-

Note: This article incorporates the handout prepared by the class for the final public presentation of the project in Redding. acre parcel of land on the Sacramento River that presented a prime location for a development based on a bold fresh new vision for the future of the area. Les Melburg, a local Redding architect and Cal Poly San Luis Obispo Alumni, recommended getting R2L Architects of San Luis Obispo involved because of the firm's experience with mixed-use projects. Both Melburg and R2L wanted to get the CAED involved not only because of the quality of the design and planning students, but because their work would provide them with a vision and a platform to initiate a public debate over the future of the area. These relationships resulted in a partnership through which, in a collaborative fashion, an amazing student project of professional quality resulted.

The Kutras Family Property Project has been a long time in the making. Unfortunately because of past disagreements and mistrust between the Kutras Family, The City of Redding, and the McConnell Foundation, little has been done to move forward with something special on this incredibly scenic

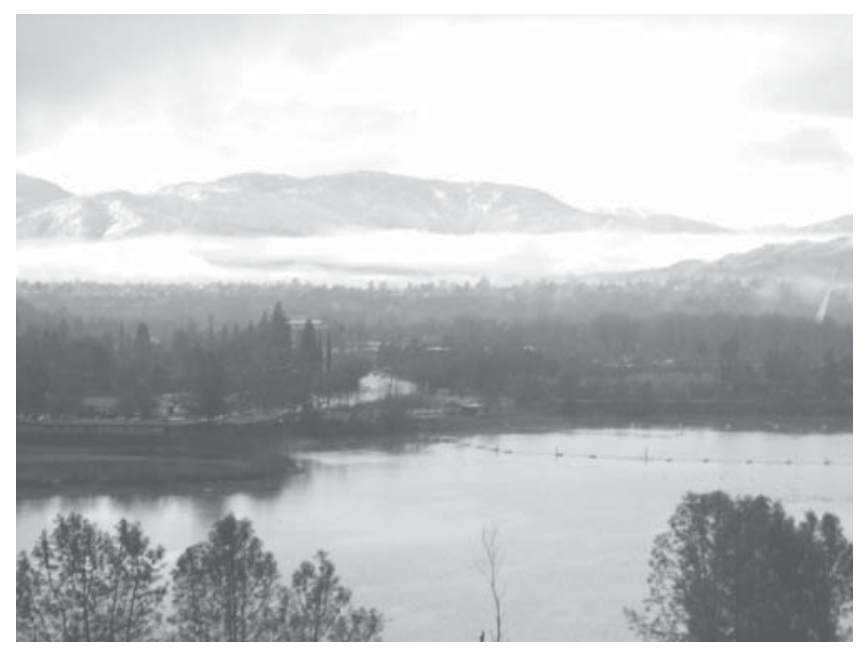

Figure 1: Part of the project area, overlooking the Sacramento River, showing Mount Shasta in the background. (photo Glenn Wood) 
and valuable piece of property. For a number of years the divisions between the groups were too large for any type of compromise to be reached. The working collaboration of the Kutras family and the McConnell foundation was a major goal that the Cal Poly Students had set out for themselves,

In early 2005, when the Cal Poly students were brought on board to re-envision the site, a major goal of the student-study team was to create a plan that would serve as a new common ground to allow all the disparate parties to try to come together and create something truly special for the community.

\section{The Process}

Our planning and design process began with a complete analysis of the site and its historical background; community needs, and market demands. A group of graduate students, their CRP professor, and three professionals from R2L traveled to Redding for an initial assessment of the site and its development potentials, the Park Marina Drive area and the local community. This visit allowed us to gather fundamental data (such as GIS mapping, existing plans, zoning, aerial photos, etc) and to meet with stakeholders to initiate the planning process; meetings were held with representatives from the City, local McConnell Foundation, and the Chamber of Commerce. Studies during this initial visit included systematic observations and mappings of the site, its vicinities, and the city, besides conducting interviews and discussions with residents and visitors. An initial survey was administered, consisting of interviewing thirty-two people at various locations in Redding on their perceptions and expectations regarding development in Redding and in the Park Marina area.

The visit to Redding also allowed us to meet with editors of the local newspaper, The Record Searchlight, who decided to support our work since they recognized the future potential of the project site. Based on the initial survey conducted in the site, a revised and more focused twenty-two question survey was posted online allowing residents to share their opinions about the revitalization of the riverfront and development in the project site. The online survey was promoted in an article we wrote specially for the Record Searchlight article on February 6, 2005. After only ten days the survey website had received 864 online responses as well additional e-mails and letters. This high rate of responses indicated a community that was truly interested and wanted to be involved with the future of their city. They shared with us their perceptions about the site as it now exists, their preferences for its future design, and other thoughts on how future developments should look like in the area. The results of the online survey were divulged to the community in an article published in the Record Searchlight.

\section{The Proposal}

Building upon all the information that was made available to us, from the various local contacts, the initial site analysis, and the incredible amount of community input gathered from the surveys, the team developed a program for the project area. After long hours of analyzing the data and responses from the community a design began to take form. The program included not only a set of goals, objectives, and design concepts, but also a vision for the project:

The intent of the Park Marina Area Concept Plan is to revitalize Redding's riverfront and create a unique place that is a destination for both the community and visitors. Sustainability, vitality, and social interaction will be facilitated by providing an array of compatible wateroriented recreational and cultural uses that are accessible to all segments of the community.

The project incorporated all of the natural beauty the site had and looked to emphasize all of the potential it held for the future of the area and region. Although the vast majority of the site will be kept for open space, the project also provides ways for developers to create economic plans that will fit well in the community that is one of the established goals of a truly mixed-use development. The Park Marina Area Concept Plan creates a three-tiered redevelopment design that includes the riverfront area, the Convention Center and Turtle Bay Museum, and the Downtown areas of the City of Redding.

The plan includes open spaces connected by pedestrian and bicycle trails which are easily accessible to the public. Paths were designed to connect with existing trail systems that link the neighborhood to the south of the proposed project and the

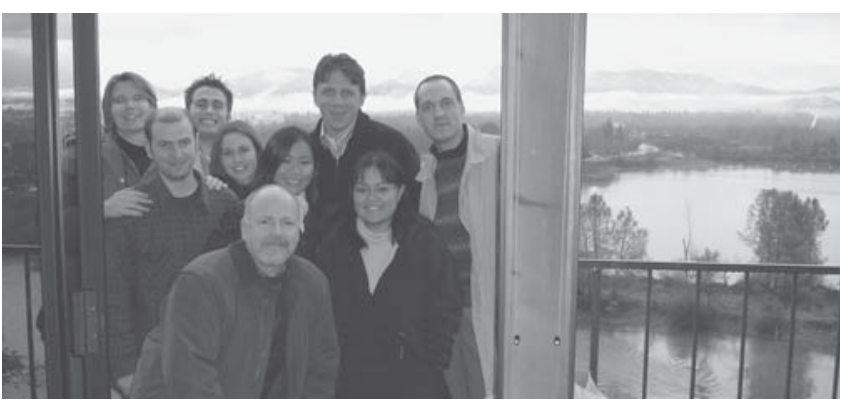

Figure 2: The group of students and the instructor during a visit to Reddding: the project area and the Sacramento River are in the background. (photo by Glenn Wood) 
Turtle Bay Exploration Center and Sundial Bridge just north of the site. The new and existing paths will meander along the water's edge revealing picturesque views of the river. Pedestrians will also be able to enjoy scenic vistas along the boardwalks and piers that will be created as part of the new project. Park Marina Drive, an established thoroughfare, has been redesigned as boulevard-type street to include two travel lanes, a landscaped median, and parallel parking, creating a pedestrian friendly environment. Wide, tree lined sidewalks designed at a pedestrian scale have also been included along Park Marina Drive.

Of the 27 acres in the Park Marina area, 18 acres will be dedicated to open space for various recreational uses. New development on the site will include:

- a 6,000 square foot outdoor amphitheater;

- a 12 screen theater complex;

- 145 residential units of different types and sizes;

- two hotels and a bed-and-breakfast;

- a marketplace with eateries, small scale development, a permanent outdoors facility for weekly farmers' markets and seasonal craft fairs, an arts plaza;

- 1,000 parking spaces in two new three-story garages on Park Marina Drive;

- traffic calming measures along the whole project site and a pedestrian bridge;

The Concept Plan was divided into three sub-areas: the Northern, Central, and Southern Sections. The Northern Section of the site includes housing and mixed-use developments that are oriented toward the river. All of the homes are situated to best take advantage of the natural beauty the site has to offer. A strong sense of place has been

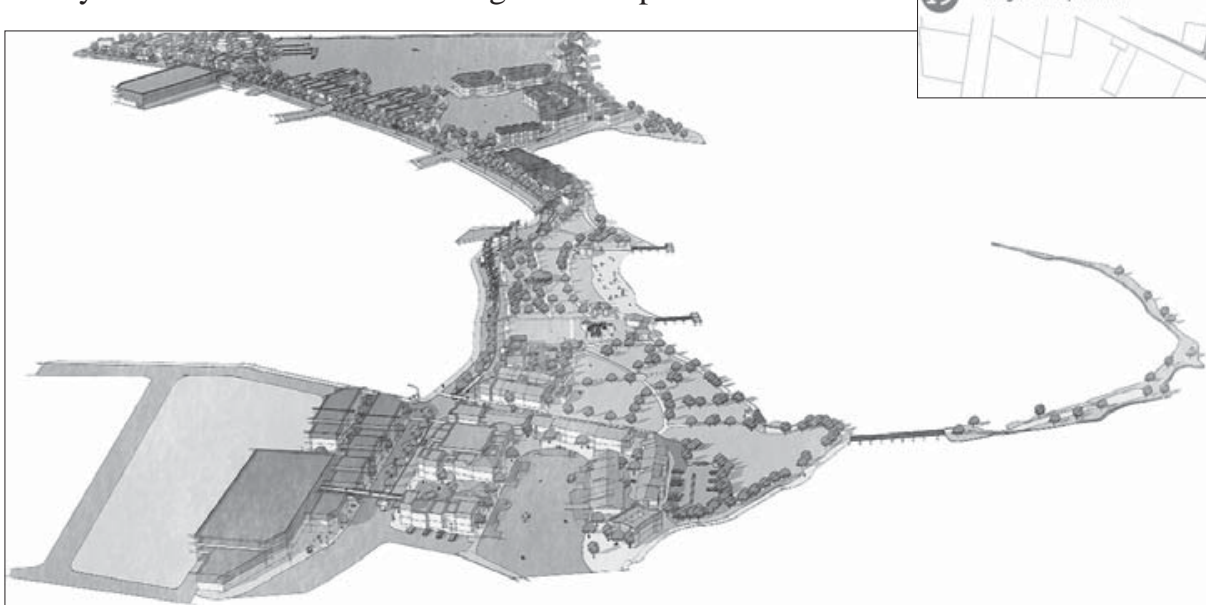

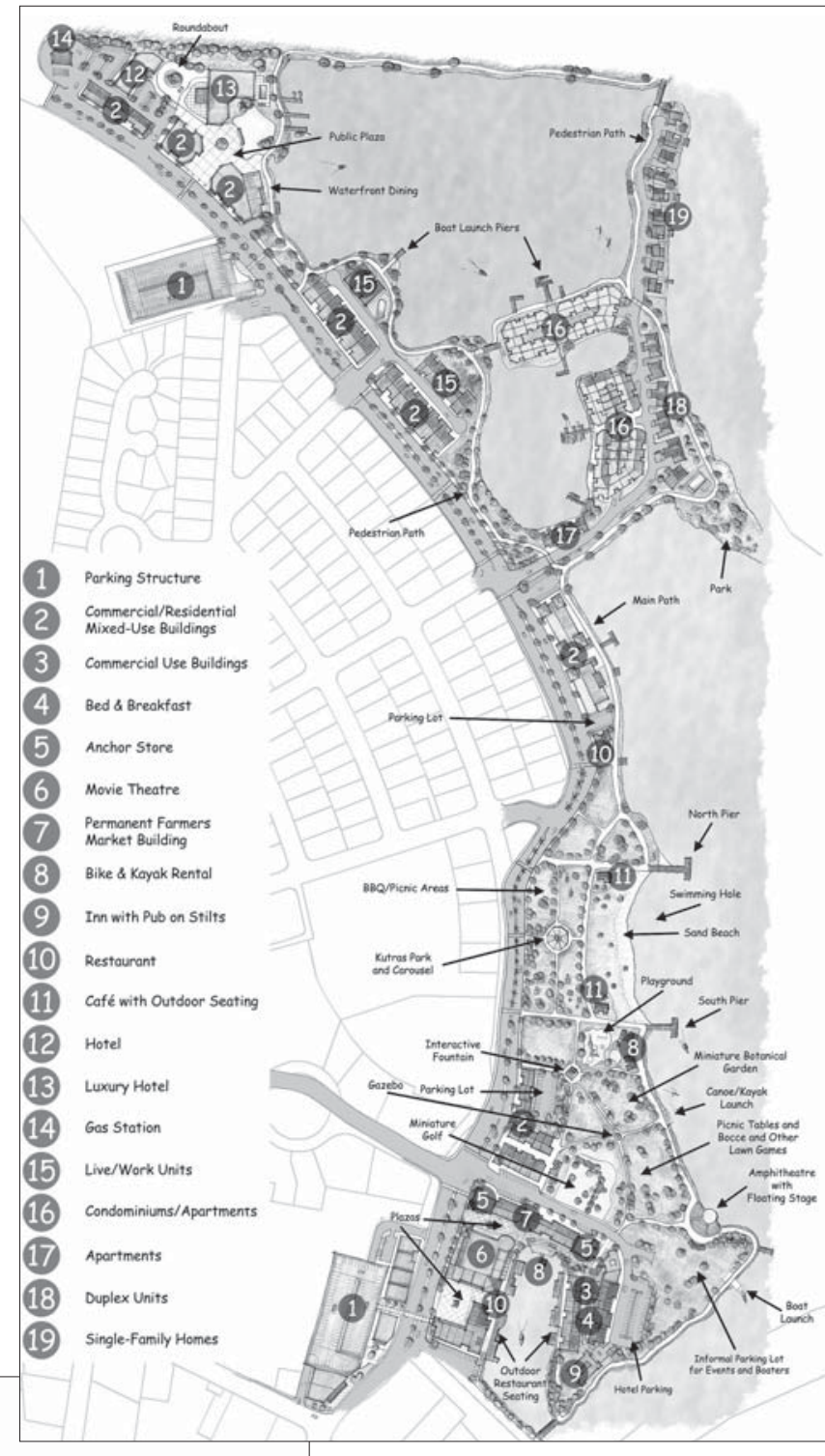

Figures 2 \& 3: Site Plan and 3D model (SketchUp) of the concept plan. 
created through the integration of public plazas, seating areas, paths and greenways, which will make the additions easily recognizable as a new and unique area in the city.

The Central Section is predominantly reserved for open space and recreational uses, including a formal park with an old fashioned merry-go-round, a water-feature sculpture, a beach, playgrounds, and bike rental kiosks. Barbecue pits, tables, seating and other facilities are also included to encourage visitors to stay and enjoy the scenic views while eating a meal.

The Southern Section of the plan creates an exciting, vibrant, and pedestrian-friendly place. It includes unique features such as the Marketplace, with small shops and restaurants. Along with the bed-and-breakfast buildings, the Marketplace surrounds a small existing water inlet that also creates a new distinct place to visit. The Southern Section also includes an outdoor amphitheater with a floating stage, and a boat ramp for easy access to the river.

The geography of the site was also taken into consideration when this plan was created; a conscious effort was made to avoid placing structures in the existing floodplain. The design quality and the composition of The Park Marina Area Concept Plan will attract a mix of uses, activities, and people to a high quality environment that will integrate the riverfront into community life, create a new destination in Redding, attract tourists, and help revitalize the western part of the downtown, bringing Redding back to the river.

\section{Final Remarks}

Besides trying to meet the goals and needs of the Kutras Family within the graduate course's pedagogical objectives, the class strove to incorporate the visions and ideas on what type of development the public felt should be pursued on the waterfront, particularly as expressed through the on-line survey. The class created a comprehensive and feasible design idea for the site and presented this vision to the community.

Redding's Record Searchlight published an extensive and illustrated first-page article on the local section titled "Designs shape riverfront - Students will unveil plan for Park Marina on Saturday" setting the stage for a public presentation. A couple of days after this article, a group of students from the class and their instructor presented the plan to over 100 community members at the Shasta County Administration Center. On this same day, the newspaper was publishing an article with a very positive evaluation of the project and support for the implementation of its vision. The public was extremely enthusiastic during the presentation and supported in full the students' project. On the day after the presentation, the news headlines were "Student project enthralls - residents cheer ideas to recast Park Marina". Evidently the clients, the Kutras family, were very happy with the results and understood them as doors opening for a future sustainable and community-friendly development of their property.

Since then, a lot of progress on this site development occurred. Several articles in the local newspaper recognized the superiority of Cal Poly's plan over the existing specific plan for the riverfront area, particularly for providing a humanistic approach, more recreational and public uses, smarter land uses, and much less land dedicated to parking. The City of Redding appointed a citizens committee chaired by a city councilor and including the assistant city manager to pursue a public consensus on the development of the Kutras' riverfront property and Cal Poly's vision.

The working collaboration of the Kutras family and the McConnell foundation was a major goal that the class had set out for themselves, but were unsure if it could be realized based on the previous diverting perspectives of the two groups. Even this seemingly lofty goal has been achieved. Public meetings and discussions have evolved and have moved forward with the McConnell Foundation and the Kutras family striving to put aside their past differences and work together. Now the two sides meet regularly as each group has obvious interests in the development and both will gain by its successful completion.

In the final analysis, the Cal Poly students under the guidance of their professor and R2L Architects not only created a new comprehensive vision for future development of the riverfront area in Redding but also created a project that was able to galvanize the support of what were formerly highly polarized groups in the community. The students could never have predicted the enthusiasm with which their plan was greeted by the Redding community, and they are gratified with the knowledge that they have created something special for a community and even increased the reputation of Cal Poly's City and Regional Planning graduate program. The students' achievement is further testimony to the value of Cal Poly's learn-by-doing philosophy and of the CRP department's community outreach projects. 

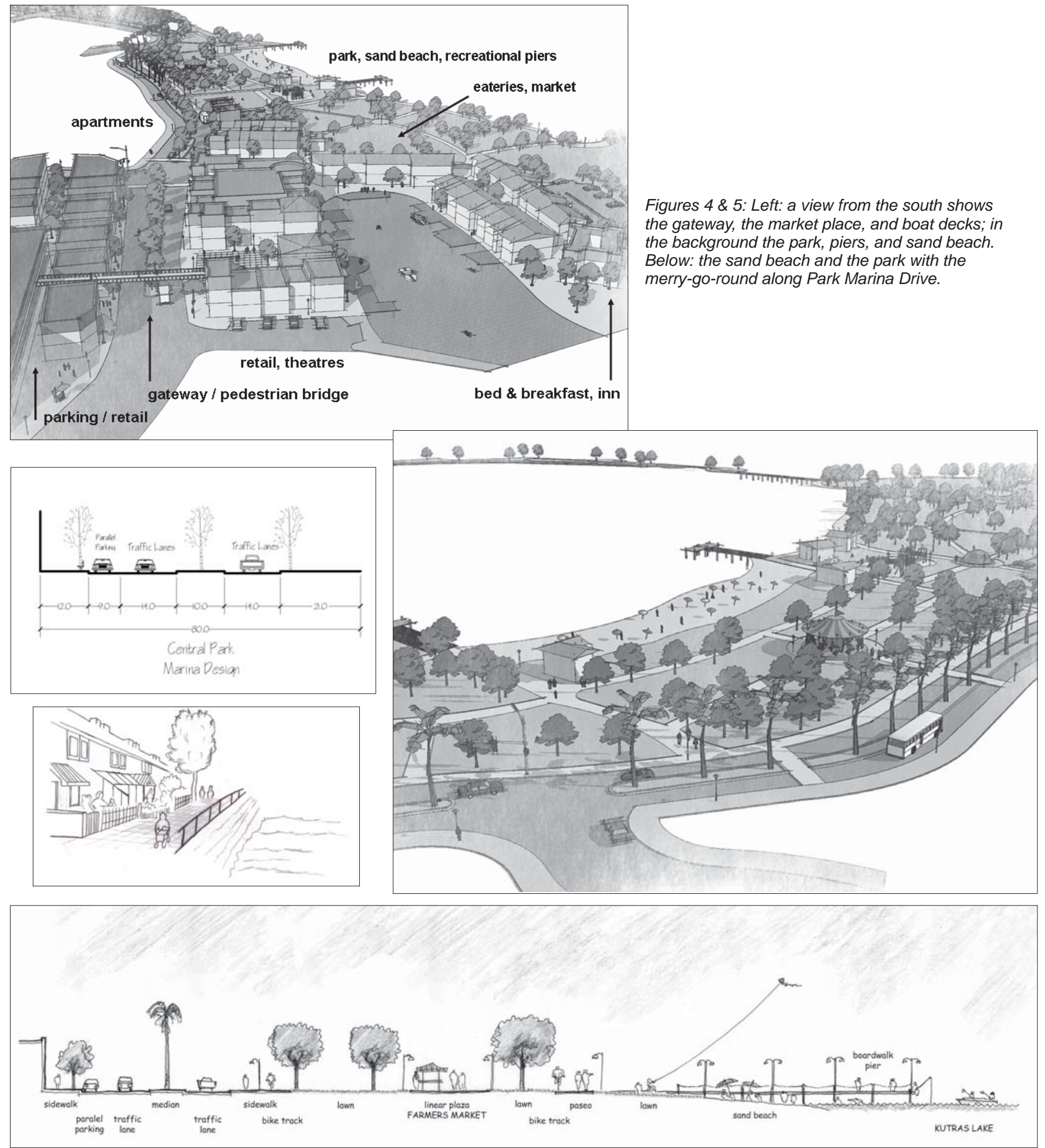

Figures 6 to 8: Sketches showing design concepts, and a section through Park Marina Drive, the public park, a pier and the sand beach. 